\title{
Let's talk about sex
}

Citation for published version (APA):

de Munnik, S. E. S., den Daas, C., Ammerlaan, H. S. M., Kok, G., Raethke, M. S., \& Vervoort, S. C. J. M. (2017). Let's talk about sex: A qualitative study exploring the experiences of HIV nurses when discussing sexual risk behaviours with HIV-positive men who have sex with men. International Journal of Nursing Studies, 76, 55-61. https://doi.org/10.1016/j.ijnurstu.2017.09.002

\section{Document status and date:}

Published: 01/11/2017

DOI:

10.1016/j.jinurstu.2017.09.002

Document Version:

Publisher's PDF, also known as Version of record

\section{Document license:}

Taverne

\section{Please check the document version of this publication:}

- A submitted manuscript is the version of the article upon submission and before peer-review. There can be important differences between the submitted version and the official published version of record.

People interested in the research are advised to contact the author for the final version of the publication, or visit the DOI to the publisher's website.

- The final author version and the galley proof are versions of the publication after peer review.

- The final published version features the final layout of the paper including the volume, issue and page numbers.

Link to publication

\footnotetext{
General rights rights.

- You may freely distribute the URL identifying the publication in the public portal. please follow below link for the End User Agreement:

www.umlib.nl/taverne-license

Take down policy

If you believe that this document breaches copyright please contact us at:

repository@maastrichtuniversity.nl

providing details and we will investigate your claim.
}

Copyright and moral rights for the publications made accessible in the public portal are retained by the authors and/or other copyright owners and it is a condition of accessing publications that users recognise and abide by the legal requirements associated with these

- Users may download and print one copy of any publication from the public portal for the purpose of private study or research.

- You may not further distribute the material or use it for any profit-making activity or commercial gain

If the publication is distributed under the terms of Article $25 \mathrm{fa}$ of the Dutch Copyright Act, indicated by the "Taverne" license above, 


\title{
Let's talk about sex: A qualitative study exploring the experiences of HIV nurses when discussing sexual risk behaviours with HIV-positive men who have sex with men
}

\author{
S. de Munnik ${ }^{\mathrm{a}, \mathrm{b}}$, , C. den Daas ${ }^{\mathrm{b}}$, H.S.M. Ammerlaan ${ }^{\mathrm{a}}$, G. Kok ${ }^{\mathrm{c}}$, M.S. Raethke ${ }^{\mathrm{a}}$, S.C.J.M. Vervoort ${ }^{\mathrm{d}}$ \\ a Department of Internal Medicine, Catharina Hospital, Eindhoven, The Netherlands \\ b Centre for Infectious Disease Control, National Institute for Public Health and the Environment, Bilthoven, The Netherlands \\ c Department of Applied Psychology, Maastricht University, Maastricht, The Netherlands \\ d Department of Internal Medicine and Infectious Diseases, Utrecht University Medical Centre, Utrecht, The Netherlands
}

\section{A R T I C L E I N F O}

\section{Keywords:}

Focus groups

HIV

HIV-positive men who have sex with men

Nurses

Qualitative research

Sexual behaviour

Sexually transmitted infections

Theory of planned behaviour

\begin{abstract}
A B S T R A C T
Background: Despite prevention efforts, the incidence of sexually transmitted infection among HIV-positive men who have sex with men remains high, which is indicative of unchanged sexual risk behaviour. Discussing sexual risk behaviour has been shown to help prevent sexually transmitted infections among HIV-positive men who have sex with men.

Objectives: The aim of this study was to identify factors that influence whether - and how - specialised HIV nurses discuss sexual risk behaviour with HIV-positive men who have sex with men. Identifying these factors could indicate how best to improve the frequency and quality of discussions about sexual risk behaviour, thereby reducing sexual risk behaviour and sexually transmitted infections. Design: Qualitative study, focus groups among HIV nurses.

Setting: Dutch HIV treatment centres.

Participants: A purposive sample was taken of 25 out of 87 HIV nurses working in one of the 26 specialised HIV treatment centres in the Netherlands. Of the 25 HIV nurses we approached, 22 participate in our study.

Methods: Three semi-structured focus group interviews were held with 22 HIV nurses from 17 hospitals. Interviews were transcribed verbatim, and thematic analysis was performed.

Results: HIV nurses agreed that discussing sexual risk behaviour is important, but barriers were experienced in relation to doing so. In accordance with the theory of planned behaviour, attitudes, perceived norms and perceived behavioural control were all found to be relevant variables. Barriers to discussing sexual risk behaviour were identified as: dealing with embarrassment, the changing professional role of an HIV nurse, time constraints, and the structure of the consultation.

Conclusions: To improve the frequency and quality of discussions about sexual risk behaviour with HIV-positive men who have sex with men, our data suggests it would be beneficial to support HIV nurses by developing tools and guidelines addressing what to discuss and how. Using a related topic as a conversational 'bridge' may help nurses to broach this subject with their patients. This would allow HIV nurses to discuss possible risk reduction strategies, such as pre-exposure prophylaxis for HIV-negative partners, condom use, strategic positioning, or sero-sorting.
\end{abstract}

\section{What is already known about the topic?}

- Despite the implementation of various prevention programs, STI prevalence has not decreased, which is indicative of unchanged sexual risk behavior among HIV positive men who have sex with men.
- Reduction of sexual risk behavior in HIV positive men who have sex with men can be achieved if health care providers introduce the topic of sexual risk behavior during consultation.

- As HIV nurses are specifically expected to discuss sexual risk behavior, barriers identified within this group might also be relevant for other professionals in sexual health care.

\footnotetext{
* Corresponding author at: National Institute for Public Health and the Environment, Center for Infectious Disease Control, Antonie van Leeuwenhoeklaan 9, 3720 BA, Bilthoven, The Netherlands.

E-mail address: Suzanne.de.Munnik@RIVM.nl (S. de Munnik).
} 


\section{What this paper adds}

- The identified barriers that play large role in the discussion of sexual risk behavior are discomfort, lack of confidence, and lack of time and structure and are also relevant for health care workers in other specialism.

- Addressing these barriers could promote the discussion of sexual risk behavior among HIV-positive MSM, for example by providing guidelines that are in line with the current shift in HIV prevention and care.

- Although transmission of STIs among HIV-positive MSM can be reduced by discussing sexual risk behavior, it is often not readily discussed by nurses who are specialized in HIV care, even in the Netherlands, a country with an open attitude towards homosexuality, HIV-status, and sexual behavior.

\section{Introduction}

Sexual risk behaviour among HIV-positive men who have sex with men leads to an increased risk of sexually transmitted infections and onward HIV transmission to sexual partners. As sexual risk behaviour in this group is a threat for public health, several Dutch organisations (e.g. STI Aids Netherlands and the Dutch HIV Association) have developed educational programs with the aim of preventing further transmission of sexually transmitted infections, and emphasising prevention among HIV-positive men who have sex with men (SOA Aids Nederland, 2013). These educational programs have been further applied in policies that aim to support the prevention of sexually transmitted infections. Despite these programs, the prevalence of sexually transmitted infections among HIV-positive men who have sex with men has not decreased, which is indicative of unchanged sexual risk behaviour. As of May 2016, more than eighteen thousand HIV-positive people have received care in one of the $26 \mathrm{HIV}$ treatment centres currently operating in the Netherlands (The Dutch HIV Monitoring Foundation, 2016). The majority of these individuals (76\%) were men who have sex with men, and more than one third (37\%) had been repeatedly diagnosed with one or more sexually transmitted infections (Visser et al., 2016).

In practice, targeted efforts to counter the proliferation of sexually transmitted infections among HIV-positive men who have sex with men might become even more important considering the recent shift in focus to the prevention of onward HIV transmission. The focus of HIV prevention in the Netherlands - as well as internationally - has shifted to early initiation of combination antiretroviral treatment in order to prevent HIV transmission (Cohen et al., 2011). The aim of this risk reduction strategy is to achieve and maintain undetectable viral load, a medical outcome that indicates low transmission risk as well as a better clinical diagnosis. In 2015, of all patients diagnosed with HIV in the Netherlands, $88 \%$ were treated in an HIV centre. Of all patients who tested positive for HIV, 77\% received HIV treatment within four weeks of testing and $72 \%$ had an undetectable viral load within six months of starting treatment (The Dutch HIV Monitoring Foundation, 2016). Another risk reduction strategy is the provision of pre-exposure prophylaxis (PrEP) to prevent HIV infections among high-risk HIV-negative people (McCormack et al., 2016). PrEP has been effective in preventing HIV infections, but efficacy does depend on patients' adherence to the treatment regime. The downside of these preventive measures is that they could reduce inhibitions to engage in sexual risk behaviour and thus in turn might actually raise STI positivity rates (Scott and Klausner, 2016).

\section{Background}

To try and put a halt to the increasing incidence of sexually transmitted infections among men who have sex with men, several studies have been conducted in recent years to gain insight into determinants that influence sexual risk behaviour among HIV-positive men who have sex with men. The objective of these studies was to identify determinants that can be converted into tailor-made interventions designed to prevent the transmission of sexually transmitted infections (Centre for disease control and prevention, 2003; Carter et al., 2014; Morin et al., 2004). Some studies have shown that a reduction of sexual risk behaviour in HIV-positive men who have sex with men can be achieved if health care providers introduce the topic of sexual risk behaviour during consultation (Crepaz and Marks, 2002; Johnson et al., 2008; Richardson et al., 2004).

While discussing sexual risk behaviour can lead to a reduction in this behaviour, studies have also shown that prevention counselling is frequently neglected in clinical practice (East and Hutchinson, 2013; Gardner et al., 2008; Mayer et al., 2004; Morin et al., 2004). Several studies conducted in the United States have focused on the reasons why health care providers avoid discussing sexual risk behaviour with their patients. Reasons for not discussing sexual risk behaviour have been identified as: time constraints, difficulties in obtaining the patient's sexual history, language and cultural barriers, and patient confidentiality concerns (Morin et al., 2004; Gerbert et al., 1999; Myers et al., 2004; Steward et al., 2006). In contrast to these findings, Marks et al. (2002) reported that health care providers were generally comfortable with discussing sexual risk behaviour. Nevertheless, they also mentioned 'lack of structure and guidelines', and 'lack of training' as practical reasons for not discussing sexual risk behaviour. Apart from these more practical concerns, it has been reported that discussing sexual risk behaviour can be hampered by the idea that men who have sex with men will not listen anyway - a belief that has been labelled provider fatalism (Gerbert et al., 1999; Steward et al., 2006).

As most of these studies were conducted in the United States, the results may not be generalisable to European countries and specifically the Netherlands, where the social context is liberal and more open towards the discussion of sexual behaviour in general and sexual risk behaviour in particular. Politically and culturally, the majority of Dutch residents adhere to the notion of freedom for all individuals, as long as this freedom does not limit the freedom of other people. This also includes an open attitude towards homosexuality, HIV status, and sexual behaviour (Widmer et al., 1998). Therefore, exploring barriers to the discussion of risk behaviour (such as unprotected anal intercourse among men who have sex with men) in the Dutch context can provide valuable new insights into the prevention of sexually transmitted infections.

Moreover, it is worth noting that the barriers identified in American studies may not be applicable to the Dutch context, because in the Netherlands, HIV patients are counselled by specialised HIV nurses. These nurses work in specialised HIV treatment centres, where patients see a doctor for their medical needs and an HIV nurse for additional support and care, including the discussion of sexual risk behaviour. Specialised HIV nurses provide HIV patients with care that may go beyond their medical needs, for example assisting with issues concerning medication adherence, providing social support (i.e. discussing minor psychological issues, depression, stigmatisation, and drug-related questions), and advising on lifestyle choices. The national organisation of nursing consultants in HIV care (VCH) has set up guidelines for discussing the specific topics of adherence to treatment and sexuality. These include nursing interventions, which provide nurses with direction in terms of how to discuss and improve adherence to treatment and how to address sexual dysfunction among their patients (Vervoort, 2009; Aidsfonds, 2008; Professional Association of Dutch HIV nurses professional, 2015). Despite the availability of guidelines for discussing topics such as sexual risk behaviour, it is possible that some HIV nurses are unaware of the content of these guidelines, or that others do not implement them (Vervoort et al., 2010). As HIV nurses are specifically expected to discuss sexual risk behaviour, identifying barriers within this group might also be relevant for other professionals in sexual 
health care (East and Hutchinson, 2013).

The aim of our qualitative study was to identify factors that influence specialised HIV nurses' decisions about whether or not to discuss sexual risk behaviour with HIV-positive men who have sex with men. In order to gain more insight into what influences Dutch HIV nurses in terms of whether they discuss sexual risk behaviour, an elicitation procedure with open questions was used to identify possible. The theory of planned behaviour (TPB/RAA) was applied as a theoretical framework in the analysis of the results. The theory of planned behaviour states that intention, one of the immediate determinants of behaviour, depends on three constructs: attitudes, perceived norms and perceived behavioural control, all of which are influenced by underlying beliefs. Fishbein and Ajzen (2010) posit that the influences of other, external variables (e.g. age, gender, education) are mediated by these three constructs. Nevertheless, we felt that it was important to explore the possible influence of these external variables (Bartholomew Eldredge et al., 2016).

The theory of planned behaviour was used as guidance to identify which factors influence HIV nurses' intentions by exploring their attitudes, perceived norms and perceived control regarding the discussion of sexual risk behaviour with men who have sex with men, as well as identifying the effects of certain external variables. Insights into the influence of these determinants on whether and how to discuss sexual risk behaviour can be used to develop interventions to improve the quality of the consultations between HIV nurses and their patients.

At the same time, however, our study procedure was designed to ensure an open approach (Ajzen, 2015). Fishbein and Ajzen (2010) have described in detail how an elicitation procedure should be executed, starting with qualitative individual and/or group interviews. We therefore organised focus groups to explore the factors that influence HIV nurses' intentions to discuss sexual risk behaviour with HIV-positive men who have sex with men using the nurses'frame of reference.

\section{Methods}

\subsection{Sample}

We selected a purposive sample of HIV nurses who deliver care for HIV infected men who have sex with men and are working in one of the 26 specialised HIV treatment centres in the Netherlands. To obtain a maximum variation sample, we made sure that participants differed according to gender, age, sexuality, education and number of years of working experience. All Dutch HIV nurses and nurse practitioners have a general nursing background (Dutch $\mathrm{HBO}-\mathrm{V}$ ), comparable to that of advanced Nurse Practitioner in the United Kingdom. Furthermore, all Dutch HIV nurses have completed additional master classes focusing on HIV care, and the topics treated in these classes include discussion of sexual health and motivational interviewing. There are additional courses that nurses can opt to attend which focus specifically on sexuality in the broadest sense, and also in relation to sexual dysfunctions, or drug use. We therefore assumed at least an adequate knowledge and skills base in relation to the discussion of sexual risk behaviour in our entire sample of HIV nurses.

\subsection{Data collection}

Semi structured focus group interviews were performed to investigate HIV nurses' perspectives on how to broach the subject of sexual risk behaviour. An interview guide was used as a framework to make sure that all topics were discussed. The topic list was based on existing literature on the discussion of sexual risk behaviour and on a behavioural theory - the theory of planned behaviour. As we alternated between data collection and analysis, the interview guide was adjusted on the basis of the themes that emerged. All focus groups started with an introduction about the objectives of the study and an explanation of the role of the participants during the focus group session. Each focus group interview started with the same opening question: 'Can you tell us what you are currently doing to discuss sexual risk behaviour among HIV-positive men who have sex with men, and any other subject relevant to this discussion?'

Each focus group was led by the same facilitator (EdM), a nurse practitioner in HIV care, and was attended by an experienced observer (SV), who also made field notes. Based on the HIV nurses' narratives, the topics they mentioned were explored in depth, by asking probing questions. The interviewer asked about all of the topics listed in the interview guideline if they had not already been brought up spontaneously by the participants. Throughout the study, we continuously integrated and discussed themes from preliminary analyses of the previous focus group (or groups) in order to identify commonalities and differences between participants.

Finally, participants were asked to provide information on their age, gender, sexual orientation, function (either HIV nurse or nurse practitioner), the number of years working in the field, and whether they had attended any training about sexual health in particular. All focus group interviews were audiotaped.

In total, three focus groups were conducted in a meeting room at the central station in Utrecht, the Netherlands. These meetings took place between November 2013 and January 2014. The focus group comprised of eight, eight, and six participants respectively. The sessions lasted an average of $105 \mathrm{~min}$ (range 90-120 min). Focus group interviews were discontinued when, during the analysis, the third focus group did not uncover any new ideas or insights into the themes, and thus saturation had been reached. Further sampling was not necessary.

\subsection{Analysis}

Data were analysed by two researchers (EdM, RM) according to the thematic analysis method described by Braun and Clarke (2006), and were discussed with a third researcher (GK). All focus group interviews were transcribed verbatim. The analysis was carried out following the six stages of thematic analysis in order to establish meaningful patterns. During the first stage, 'familiarisation with data', the interviews were read out in full, and then read again in order to grasp the finer details. In the second stage, initial codes were generated and meaningful paragraphs were open coded. In the third stage, both researchers searched for themes among the codes, leading to categorisation based on similarities. In the fourth stage, overall themes were assigned and reviewed, leading to the fifth stage which involved defining and naming the themes. In this stage, the framework of the theory of planned behaviour was applied to explore the themes (in relation to attitudes, subjective norms and perceived behavioural control). The third researcher (GK), an expert in the field of psychology, was involved in the process of categorising and interpreting the data. After the second focus group, the two researchers discussed the initial findings with the third researcher in terms of which themes were as expected, and any new themes were discussed.

Data analysis was supported by means of the software program ATLAS.ti 7.0 (Scientific Software Development GmbH Berlin). Based on the outcomes of these stages, the final report was produced in the sixth and final stage of the analysis.

\subsection{Ethical considerations}

The study followed the prevailing guidelines for ethical approval in the Netherlands (CCMO website, 2017). Consent was obtained with the participants' positive response to an email requesting study participation, which included information about the study and the study aims. Anonymity of the respondents was guaranteed. Data and results could not be traced back to individual participants. 
Table 1

Demographic characteristics of HIV-nurses N(\%).

\begin{tabular}{lll}
\hline Characteristic $(\mathrm{N}=22)$ & \\
\hline Age (yrs) & Mean (range) & $50(28-64)$ \\
Gender & Female & $14(64 \%)$ \\
Sexuality & Heterosexual & $15(68 \%)$ \\
Years in clinical practice (yrs) & Mean (range) & $12(2-25)$ \\
Provider type & HIV nurse* & $12(55 \%)$ \\
Training received in discussing sexuality & Yes & $13(59 \%)$ \\
\hline
\end{tabular}

Note: *The remaining 10 were HIV nurse practitioners.

\section{Results}

\subsection{Participants}

Of 25 selected HIV nurses who were approached by e-mail, 22 participated in our study. Three HIV nurses declined to participate citing lack of time. Fourteen of the 22 participants were women (all heterosexual) and eight were men (one heterosexual). They were aged between 28 and 64, and they had, on average, worked in HIV care for 12 years (range 2-25 years). They worked in 17 of the 26 specialised HIV treatment centres. The characteristics of the HIV nurses are described in Table 1.

The discussion of sexual risk behaviour by HIV nurses was found to be influenced by seven themes (Table 2). These themes are presented according to the three determinants of the theory of planned behaviour, namely attitudes towards the discussion of sexual risk behaviour, perceived norms about the discussion of sexual risk behaviour, and perceived behavioural control with regard to the discussion of sexual risk behaviour. A fourth category comprises external variables. The themes are described below and illustrated with relevant quotes.

\subsection{Attitudes towards the discussion of sexual risk behaviour}

\subsubsection{Dealing with embarrassment}

HIV nurses experienced feelings of embarrassment and a sense of discomfort regarding the idea of discussing sexual risk behaviour. These feelings often created a barrier to the discussion of sexual risk behaviour. Participants were particularly uncomfortable about the intimate aspect of discussing sexual risk behaviour. As one HIV nurse put it, ' $I$ often think: Who am I to ask the patient about such an intimate matter? Why should they [the patients] share that with me?' Furthermore, talking about sexual risk behaviour 'out of the blue' was assumed to cause feelings of embarrassment in participants. As one participant put it: 'If the patient himself starts talking about sexuality, I feel less embarrassed about discussing this than when I bring up the subject myself.'

Due to these kinds of experiences, most participants tried to find some sort of reason for introducing the subject of sexuality: 'I regularly use some introductory remarks to make me feel more comfortable discussing sex.' Alternatively, HIV nurses attempted to put the patient at ease verbally and non-verbally, for example by asking open questions in a

Table 2

Determinants that influence whether or not sexual risk behaviour is discussed.

\begin{tabular}{ll}
\hline TPB classification & Themes \\
\hline Attitude & 1. Dealing with embarrassment \\
& 2. Striving for an equal relationship with the \\
patient & 3. Changing professional role of the HIV nurses \\
Perceived norms & 4. When to raise a topic \\
& 5. Prioritising abundance of relevant topics \\
Perceived behavioural & topics \\
control & 7. Connecting with patients through similarities \\
External variables & in individual characteristics \\
\end{tabular}

non-judgemental way. One participant gave the following example: ' $I$ intentionally use open questions and try to be as specific as I can in communicating sexual risk behaviour by using the words bare backing, or by specifically mentioning ejecting semen into the anus, group sex, fisting, or rimming.' Other HIV nurses said that they specifically ask the patient's permission to talk about the subject during the consultation instead of using open questions.

\subsubsection{Striving for an equal relationship with the patient}

HIV nurses stated that they did not want to be patronising. They considered being equal to be the basis for a trusting relationship with their patient and a prerequisite for high-quality health care. They expressed the fear that a patient might stop showing up for his appointments if they were too patronising or did not give the patient the feeling of being an equal. Having a relationship of trust with a patient was mentioned as both a facilitator and a barrier in terms of discussing sexual risk behaviour. As one participant explained: 'There are patients I have given counselling to for more than ten years. I know them so well, that makes it difficult to bring up this topic'. Another participant said: 'In fact, I dare to ask about sex because I've known my patients for a long time and I can weigh up the situation in terms of whether they can handle this kind of subject or not'.

\subsection{Perceived norms regarding the discussion of sexual risk behaviour}

\subsubsection{The changing professional role of HIV nurses}

In recent years, the role of the HIV nurse has shifted, with half of the group specialising in order to be able to combine nursing and medical care. The participants believed that discussing sexual risk behaviour is clearly part of their job, due to the relationship between HIV and sexuality. This perceived norm was mostly supportive of discussing sexual risk behaviour. This is in line with the guidelines of the national professional organisations in health care which stipulate that HIV nurses need to discuss sexual risk behaviour. On the one hand, one participant stated: 'I believe that we, as nurses, should be able to freely and openly discuss HIV and sex, and should, in fact, be open to discussing it over and over again.' On the other hand, participants also explained that even though they are aware of the norm to discuss sexual risk behaviour, they nevertheless sometimes still avoid this topic: 'To me it's not clear what I need to discuss exactly about this topic, or how thoroughly I should explore it. It was more a matter of personal interest [affinity with the topic in relation to the specific patient] whether or not I brought up this topic. After I followed a course, I became more aware of this.'

\subsubsection{When to raise a topic}

While HIV nurses believe that it is their role to discuss sexual risk behaviour, it is less clear to them how, when, and how often the topic should be raised. The uncertainty felt in relation to their consultations was handled using different strategies. Among some HIV nurses, this sometimes leads to talking about irrelevant issues: 'With patients that have been in care for many years, I expect to know everything, and then we just chitchat.' One participant mentioned that, among colleagues, they decided to make sexual risk behaviour a key topic to be discussed annually: 'We realised that we don't discuss this topic often, but one year ago we decided to discuss this topic during an evaluation session that we would plan one year after the patient started to attend consultations.' The importance of discussing sexual risk behaviour was also highlighted by another participant, who summed up her concerns: 'They have been treated for a sexually transmitted infection and have a low HIV viral load and still continue their sexual risk behaviour. At least they will not infect someone else in the near future.'

\subsubsection{Prioritising an abundance of relevant topics}

Participants also mentioned the need to address many different topics whilst providing HIV care. This is as a consequence of changes in the health care requirements of the population of HIV-positive patients, 
many of whom are healthy but aging. Our participants indicated that, in their experience, many of their colleagues prioritise other health topics over the discussion of sexual risk behaviour, due to the abundance of relevant and important topics that should be discussed. Patients visit the outpatient clinics less frequently, and when they do, other health topics are prioritised during the consultation: 'Sometimes we intentionally leave out this subject [sexual risk behaviour] because of other important matters, such as cardiovascular disease.'

Another important barrier to discussing sexual risk is the perceived norm of observing time constraints in relation to consultations. Participants state that there is often insufficient time to start discussing such a sensitive topic, particularly in light of all the other topics that need to be discussed. 'Since the new guidelines, patients visit our clinic less frequently. In practice, they come twice a year, and sometimes, if they call instead of visiting, I see them only once a year. As a result, I do not have enough time during the consultation to discuss this topic.'

\subsection{Perceived behavioural control in the discussion of sexual risk behaviour}

\subsubsection{Confidence in capacity to discuss HIV-related topics}

Skills were mentioned as a prerequisite for effective communication by several participants. Even though all HIV nurses are fully qualified for their jobs and have attended education programs specifically tailored to HIV nurses, they also need to feel confident that they are able to convey this knowledge to the patient in a way that he will understand. Specifically, participants indicated using motivational interviewing as a technique that helped them in the discussion of sexual risk behaviour: 'I probably apply motivational interviewing techniques myself. I use some elements of the technique to explore the patient's willingness to use a condom.'

Apart from conversation techniques, knowledge was also seen as an important factor influencing the discussion of sexual risk behaviour. In particular, knowledge about sexuality and drugs was mentioned as a requirement for any discussion about sexual risk behaviour. A participant illustrated this as follows: 'I realise that since I attended a training course by Mainline [Dutch authority providing training on drugs], I specifically talk to patients about drugs and use the names, such as speed, GHB and XTC or some other drug in combination with Kamagra or Viagra, and I also ask if they are top or bottom. I think that in this way, I can better understand what risks they take.'

Most HIV nurses who participated in the focus group discussions considered attending training courses to be important. Several nurses indicated that the training gave courses provided them with skills as well as knowledge and the confidence to discuss the relevant topics more easily. For example, as one nurse mentioned: 'The [sex addiction] training course made it easier for me to talk about sexuality.'

\subsection{External variables influencing the discussion of sexual risk behaviour}

\subsubsection{Connecting with patients through similarities in individual} characteristics

One factor found to negatively influence whether participants discussed sexual risk behaviour was experience of a limited connection with certain patients, due to a perceived distance based on the participant's own age, gender or sexual orientation.

. Younger participants seemed to find it more difficult to bring up the subject with older patients, and vice versa. The following comment reflects how older HIV nurses are struggling with the age of the patient: '...for me, a patient's age is of significance in terms of talking about it easily; I am somewhat older myself and find it difficult to connect to the younger generation of men who have sex with men.'

The participants also had the impression that gender plays a role in discussing sexual risk behaviour with patients. They felt that men who have sex with men find it more difficult to discuss sexual risk behaviour with a female than with a male HIV nurse. The female participants mentioned that this sometimes influenced whether or not they started a discussion about sexual behaviour

; they thought men who have sex with men would be better understood in a male-to-male conversation: 'I feel that men who have sex with men do not want to talk to me about sex due to the fact that I'm a woman, so that's why I don't always bring it up.' As another participant put it: 'I am almost 30 years older than some of my patients and therefore I am not fully aware of and up-to-date with new trends, such as the dating app Grindr. Furthermore, as a woman, I am not versed in some of the topics this patient group deals with and therefore I sometimes have trouble finding an appropriate way to start the conversation'

Moreover, participants who are themselves men who have sex with men regarded their sexual orientation as an advantage when it comes to discussing sexual risk behaviour: 'I think it is an incredible advantage that I am in the same scene, I recognise experiences of my patients and have practical knowledge of the topics they discuss.' However, the only heterosexual male participant did not regard his sexual orientation as a disadvantage. 'I am an expert in the area of sexual risk behaviour and try to explicitly discuss this with my gay patients. I do not think it is an issue that I am a straight man myself.'

\section{Discussion}

The current study explored which barriers and facilitators influence whether or not Dutch HIV nurses' discuss sexual risk behaviour with HIV-positive men who have sex with men.

Our finding that Dutch HIV nurses experience barriers in discussing sexual risk behaviour is in line with previous studies conducted in other parts of the world with nurses who have less specialised roles (Morin et al., 2004; Johnson et al., 2008; Gardner et al., 2008; Mayer et al., 2004; Gerbert et al., 1999). However, we did find some differences in relation to the current context. Our data suggests that time constraints were interpreted differently by HIV nurses. This difference can be explained by the burgeoning number of topics that need to be discussed in view of the increasing average age of the HIV population, co-morbidities, the recent shift in prevention strategies of onwards transmission, and the changing role from HIV nurse to nurse practitioner.

Although HIV nurses working in the Dutch HIV centres, (specialised in delivering care to HIV-positive patients) are the designated professionals responsible for discussing sexual risk behaviour with HIV-positive men who have sex with men, we found that some Dutch HIV nurses feel embarrassed and experience discomfort when bringing up the topic of sexuality with their patients. This indicates that the personal norms and values of HIV nurses are more relevant in terms of their ability to talk about sexual risk behavior than the rather liberal norms of the society that they are a part of. Dutch society is generally known for its open-minded attitude regarding topics such as sexual behavior and it might therefore be expected that Dutch HIV nurses would feel comfortable in dealing with these topics. However, our data suggests that this is not always the case. To reduce these feelings of discomfort, some nurses indicated that they would only discuss sexual risk behaviour if this topic was first brought up by the patient. Our findings show that one way to address this barrier could be for HIV nurses to broach other subjects - for example drug use - as a conversational 'bridge' in order to prepare the way for starting a discussion on sexual risk behaviour. It may be beneficial for nurses to first practice this approach in dedicated training courses, in which standard starting points for opening a discussion on this topic could be provided. The preparation of leaflets that include example sentences may also help nurses to start this type of conversation.

Having a long-term relationship of trust with their patients and being new in the field were both factors that led to difficulties in discussing sexual risk behaviour - the first because of knowing the patient too well and the latter due to not knowing the patient well enough to bring up this subject. Furthermore, novice HIV nurses lack the skills and experience necessary to talk about this topic, which suggests that they need specific training on how to discuss sexuality. At the same time, 
novice nurses need to develop their own professional attitude while gaining general experience in the field. Advanced HIV nurses could use a predetermined list of topics - or use another topic as a conversational 'bridge' that leads to a discussion of sexual risk behaviour.

Currently, Dutch HIV nurses receive education designed to provide the knowledge and skills required for discussing various topics, including sexual risk behaviour. Surprisingly, the training course that nurses mentioned as being most useful - and leading to high intentions to discuss sexual risk behaviour - did not specifically address sexual risk behaviour but rather focused on drugs. Interestingly, participants mentioned that discussing drug use could be used as a starting point for discussing sexual risk behaviour. The fact that this training course was mentioned (rather than one of the other specialised courses) suggests that current educational programs need to be evaluated and potentially modified and updated. This suggestion is in line with a previous study indicating that the fast changes in the field of HIV care and HIV prevention necessitate a need to modify courses more often than is presently the case (Mimiaga et al., 2007).

We found that external variables such as age, gender and sexual orientation appear to influence whether or not sexual risk behaviour is discussed.

Specifically, younger nurses and male HIV nurses seemed to be more at ease with this topic, in particular if they are themselves men who have sex with men. This could be because they feel able to communicate more easily with this group of patients, or because they have more affinity with this topic, or because they have better or different relationships with these patients, e.g. more trusting or more at ease. Of course, an HIV nurse's sexual orientation, age, or gender cannot be influenced, but female or older HIV nurses could receive additional assistance to help them form better connections with patients who they do not automatically identify with, or be trained in ways to communicate with these patients that would feel more natural. A specific example of what HIV nurses could discuss during consultation (in terms of the behaviours involved and the possible risks) is the use of apps, such as Grindr, for meeting sexual partners. Knowing the right jargon and more about the lifestyle of HIV-positive patients who are men who have sex with men is likely to be helpful in terms of discussing this topic more easily and in more depth.

The HIV nurses' confusion about the norms among their peers and managers regarding the importance of discussing sexual risk behaviour indicates that it is important to clarify the role and responsibility of HIV nurses, in order for them to provide patients with the health care they need. To achieve this, they need to be able to dedicate sufficient time and create the ideal setting for discussing sexual risk behaviour. By doing so, not only will HIV nurses improve the individual patient's health care and be able to address their specific needs, but they will also contribute to the community as a whole by preventing further HIV and STI transmission. These findings suggest a need for a re-evaluation of the current guidelines, in particular the structure of consultations, and the time available for individual consultations.

The intentions of Dutch HIV nurses regarding the discussion of sexual risk behaviour with HIV positive men who have sex with men are influenced by different facilitating and hindering factors that, from a theoretical perspective, are consistent with the theory of planned behaviour. First, embarrassment and the need to strive for an equal relationship with the patient were emerging themes that are related to attitudes. Second, themes applicable to perceived norms were related to the HIV nurses' understanding that discussing the topic is part of the changing professional role of the HIV nurses. Perceived norms were also related to timing (when to raise the topic), and nurses' difficulties in prioritising the abundance of relevant topics that could or should be discussed during consultations

Finally, confidence in the capacity to discuss sexual risk behaviour and possession of the relevant knowledge and skills - were related to perceived behaviour control.

While the present study focused on factors that influence whether or not HIV nurses discuss the topic of sexual risk, the exact content of this discussion is open to debate. The discussion of sexual risk behaviour can be considered from many different angles. (Brawner et al., 2016). In relation to reducing the number of sexually transmitted infections, such a conversation should involve several topics. HIV nurses could discuss sexual behaviours in general, and how these affect risks for sexually transmitted infections - for example, the number of partners, sexual acts, drug use, and disclosure of serostatus or viral-load to partners. HIV nurses could discuss the patient's own behaviour and possible risk reduction strategies, such as PrEP for their HIV-negative partners, condom use, strategic positioning, or how to successfully sero-sort.

Our current study has shed light on several factors which appear to influence the discussion of sexual risk behaviour. Future research could investigate which of these factors are most important, and how these factors might interact to influence the discussion of sexual risk behaviour. It is also worth noting that there are many options available in terms of the discussion of sexual risk behaviour, some of which may be more appropriate for certain patient groups (for example men who have sex with men), and others which may be easier for HIV nurses from a particular demographic to implement. It is important to further investigate the circumstances in which sexual risk behaviour is discussed, what exactly is discussed, and how effectively this topic is discussed.

The findings of this study present an opportunity for improving sexual health care among HIV-positive men who have sex with men by helping HIV nurses to improve the frequency and quality of any discussion of sexual risk behaviour with their patients. Achieving an understanding of the factors that influence whether or not this topic is discussed is essential groundwork for further research.

Quantitative research is therefore necessary to assess the themes and to validate the most important determinants.

\subsection{Strengths and limitations}

It should be noted that the 22 HIV nurses that participated in this study were not from all regions of the Netherlands. However, the participants did work in various hospitals with different levels of urbanisation, and it is possible that this difference in level of urbanisation could have influenced whether ot not the HIV nurses' discussed sexual risk behaviour.

For example, levels of stigmatisation could be higher in regions with lower urbanisation levels. However, the different levels of urbanisation were adequately represented in this study.

The lead researcher in this study is an experienced HIV nurse practitioner, who sees patients regularly and who has learned to critically assess current nursing care of HIV patients by carrying out indepth research. As the researcher is an active member of this target group, a clear strength of this project is that members of the target group were very willing to participate and were able to see the importance of this research topic. A possible limitation is that the researcher's expectations - which her colleagues may have been more sensitive to - could have influenced the results To counter any effect of experiment bias, another researcher took on the role of moderator in the focus groups. This moderator is an experienced researcher in qualitative research and is also familiar with the field of HIV care in the Netherlands. This experience enabled the moderator to provide continuity in conducting the focus groups. Moreover, as she was less well known to the nurses, she was less likely to influence the participants' responses to the topics discussed. In our study, we did not investigate barriers and facilitators related to discussing sexual risk behaviour from the perspective of the patients (i.e. HIV-positive men who have sex with men), but rather from the perspective of the HIV nurses. Future research should explore patient perspectives in order to understand how patients experience discussing sexual risk behaviour with their HIV nurse, and to gather their opinions on how this could be improved. 


\section{Conclusion}

Our findings indicate several important themes that influence whether or not HIV nurses discuss sexual risk behaviour with their patients (HIV-positive men who have sex with men). To improve the frequency and quality of discussions about sexual risk behaviour, our data suggests it would be beneficial to support HIV nurses by developing skills, tools, and guidelines in relation to what is discussed and how. Using a related topic as a conversation 'bridge' could assist nurses in broaching this subject. External variables such as age, gender and sexual orientation appear to influence whether or not sexual risk behaviour is discussed.

Knowing the right jargon and being familiar with the lifestyle of HIV-positive patients who are men who have sex with men may encourage nurses to discuss this topic more easily and in more depth. We suggest that further research should also explore patients' perspectives on discussing sexual risk behaviour with their nurse.

\section{Conflict of interest statement}

None declared.

\section{Acknowledgements}

We would like to thank Bibi de Zeeuw for assisting with the thematic coding. In addition, we would like to thank the nurses who participated in the focus groups for their great input. This study is funded by the Aids Fonds (grant 2014046). No competing financial interests

\section{References}

Ajzen, I., 2015. The theory of planned behaviour is alive and well, and not ready to retire: a commentary on Sniehotta, Presseau, and Araújo-Soares. Health Psychol. Rev. 9 (2), 131-137.

Bartholomew Eldredge, L.K., Markham, C.M., Ruiter, R.A.C., Fernández, M.E., Kok, G., Parcel, G.S., 2016. Planning Health Promotion Programs: An Intervention Mapping Approach, 4th edition. Jossey-Bass, San Francisco, CA ISBN-13: 978-1119035497.

Braun, V., Clarke, V., 2006. Using thematic analysis in psychology. Qual. Res. Psychol. 3 (2), 77-101. http://dx.doi.org/10.1191/1478088706qp063oa.

Brawner, B.M., Alexander, K.A., Fannin, E.F., Baker, J.L., Davis, Z.M., 2016. The role of sexual health professionals in developing a shared concept of risky sexual behavior as it relates to HIV transmission. Public Health Nurs. 33, 139-150. http://dx. doi.org/10. $1111 /$ phn. 12216.

CCMO website. (http://www.ccmo.nl/en/non-wmo-research).

Carter Jr., J.W., Hart-Cooper, G.D., Butler, M.O., Workowski, K.A., Hoover, K.W., 2014. Provider barriers prevent recommended sexually transmitted disease screening of HIV-infected men who have sex with men. Sex. Transm. Dis. 41 (2), 137-142. http:// dx.doi.org/10.1097/OLQ.0000000000000067.

Centre for disease control and prevention (CDC), 2003. Incorporating HIV Prevention into the Medical Care of Persons Living with HIV. Recommendations of CDC, the Health Resources and Services Administration, the National Institutes of Health, and the HIV Medicine Association of the Infectious Diseases Society of America. MMWR Recomm. Rep. 52, 1-24.

Cohen, M.S., Chen, Y.Q., McCauley, M., Gamble, T., Hosseinipour, M.C., Kumarasamy, N., et al., 2011. Prevention of HIV-1 infection with early antiretroviral therapy. N. Engl. J. Med. 365 (6), 493-505. http://dx.doi.org/10.1056/NEJMoa1105243.

Crepaz, N., Marks, G., 2002. Towards an understanding of sexual risk behavior in people living with HIV: a review of social, psychological, and medical findings. AIDS 16 (2), 135-149. http://dx.doi.org/10.1097/00002030-200201250-00002.

East, L., Hutchinson, M., 2013. Moving beyond the therapeutic relationship: a selective review of intimacy in the sexual health encounter in nursing practice. J. Clin. Nurs. 22, 3568-3576. http://dx.doi.org/10.1111/jocn.12247.

Fishbein, M., Ajzen, I., 2010. Predicting and Changing Behavior: The Reasoned Action Approach. Taylor \& Francis, New York.

Gardner, L.I., Metsch, L., Strathdee, S.A., del Rio, C., Mahoney, P., Scott, D., et al., 2008. Frequency of discussing HIV prevention and care topics with patients with HIV: influence of physician gender, race/ethnicity, and practice characteristics. Gend. Med. 5 (3), 259-269. http://dx.doi.org/10.1016/j.genm.2008.08.002.

Gerbert, B., Love, C., Caspers, N., Linkins, K., Burack, J.H., 1999. Making all the difference in the world: how physicians can help HIV-seropositive patients become more involved in their healthcare. Aids Patient Care STDS 13 (1), 29-39. http://dx.doi. org/10.1089/apc.1999.13.29.

Johnson, W.D., Diaz, R.M., Flanders, W.D., Goodman, M., Hill, A., Holtgrave, D., et al., 2008. Behavioral interventions to reduce risk for sexual transmission of HIV among men who have sex with men. Cochrane Database Syst. Rev. CD001230. http://dx.doi. org/10.1002/14651858. CD001230.pub2.

Marks, G., Richardson, J.L., Crepaz, N., Stoyanoff, S., Milam, J., Kemper, C., et al., 2002. Are HIV care providers talking with patients about safer sex and disclosure?: a multiclinic assessment. J. AIDS 16 (14), 1953-1957. http://dx.doi.org/10.1097/ 00002030-200209270-00013.

Mayer, K.H., Safren, S.A., Gordon, C.M., 2004. HIV care providers and prevention: opportunities and challenges. J. AIDS 37 (Suppl. 2), S130-S132. http://dx.doi.org/10. 1097/01.qai.0000140613.66887.0.

McCormack, S., Dunn, D.T., Desai, M., Dolling, D.I., Gafos, M., Gilson, R., et al., 2016. Pre-exposure prophylaxis to prevent the acquisition of HIV-1 infection (PROUD): effectiveness results from the pilot phase of a pragmatic open-label randomised trial. Lancet 387 (10013), 53-60. http://dx.doi.org/10.1016/S0140-6736(15)00056-2.

Mimiaga, J.M., Goldhammer, H., Belanoff, C., Tetu, A., Mayer, K., 2007. Men who have sex with men: perceptions about sexual risk, HIV and sexually transmitted disease testing, and provider communication. Sex. Transm. Dis. 34 (2), 113-119. http://dx. doi.org/10.1097/01.olq.0000225327.13214.bf.

Morin, S.F., Koester, K.A., Steward, W.T., Maiorana, A., McLaughlin, M., Myers, J., et al., 2004. Missed opportunities: prevention with HIV-infected patients in clinical care settings. J. AIDS 36 (4), 960-966. http://dx.doi.org/10.1097/00126334-200408010 00010.

Myers, J.J., Steward, W.T., Charlebois, E., Koester, K.A., Maiorana, A., Morin, S.F., 2004 Written clinic procedures enhance delivery of HIV prevention with positives counselling in primary health care settings. J. AIDS 37 (Suppl. 2), S95-S100. http://dx. doi.org/10.1097/01.qai.0000140607.36393.d3.

Professional Association of Dutch HIV nurses, 2015. Expertisegebied HIV. http://www. venvn.nl/Portals/1/Nieuws/2015\%20documenten/20151127\%20Expertisegebied \%20verpleegkundig\%20 consulent\%20hiv.pdf?timestamp $=1448636704299$.

Richardson, J.L., Milam, J., McCutchan, A., McCutchana, A., Stoyanoff, S., Bolan, R., et al., 2004. Effect of brief safer-sex counselling by medical providers to HIV-1 seropositive patients: a multi-clinic assessment. AIDS 18 (8), 1179-1186. http://dx.doi. org /10.1097/00002030-200405210-00011.

SOA Aids Nederland, 2013. Onder Controle: Strategie Voor De Aanpak Van Soa's En Hiv Onder MSM in Nederland 2013-2018. Soa Aids Nederland.

Scott, H., Klausner, J., 2016. Sexually transmitted infections and pre-exposure prophylaxis: challenges and opportunities among men who have sex with men in the US. AIDS Res. Ther. 13, 5. http://dx.doi.org/10.1186/s12981-016-0089-8.

Steward, W.T., Koester, K.A., Myers, J.J., Morin, S.F., 2006. Provider fatalism reduces the likelihood of HIV-prevention counselling in primary care settings. AIDS Behav. 10 (1), 3-12. http://dx.doi.org/10.1007/s10461-005-9024-z.

The Dutch HIV Monitoring Foundation [Dutch: Stichting HIV Monitoring], 2016. Monitoring Report 2016. Human Immunodeficiency Virus (HIV) Infection in the Netherlands. Retrievable from. http://www.hiv-monitoring.nl/nederlands/ onderzoek/monitoring-reports/.

Vervoort, S.C.J.M., Dijkstra, B.M., Hazelzet, E.E.B., Grypdonck, M.H.F., Hoepelman, A.I.M., Borleffs, J.C.C., 2010. The role of HIV nursing consultants in the care of HIVinfected patients in Dutch hospital outpatient clinics. Patient Educ. Couns. 80 (2), 180-184. http://dx.doi.org/10.1016/j.pec.2009.11.016. Epub 2009 Dec 31.

Vervoort, S.C.J.M., 2009. Adherence to HAART. A Study of Patients' Perspectives and HIV Nurse Consultants' Strategies. dissertation University of Utrecht, The Netherlands Printed: Enschede Gildeprint drukkerijen BV.

Visser, M., Van Aar, F., van Oeffelen, A.A.M., Van den Broek, I.V.F., Op de Coul, E.L.M., Hofstraat, S.H.I., Heijne, J.C.M., et al., 2016. Sexually Transmitted Infections Including HIV, in the Netherlands in 2016. Centre for Infectious Disease Control, National Institute for Public Health and the Environment (RIVM), Bilthoven.

Widmer, E.D., Treas, J., Newcomb, R., 1998. Attitudes toward nomarital sex in 24 countries. J. Sex Res. 34 (4), 349. 